\title{
Mixing and Compaction Temperature of Nanosilica Composite Polymer Modified Asphalt
}

\author{
Esraa J Al-mousawi ${ }^{1,2,3}$ | Rashaa H Al-Rubaee ${ }^{1}$ | Ammar A Shubber ${ }^{1}$ |
}

Affiliations
${ }^{1}$ Civil Engineering
Department, University of
Technology, Baghdad, Iraq.
2 Ministry of Transportation,
the General Company for
Land Transport, Baghdad,
Iraq.
Correspondence
Esraa J Al-mousawi,
${ }^{3}$ Email: $42360 @$ student.
uotechnology.edu.iq
Received
17-October-2020
Revised
11-November-2020
Accepted
21-November-2020
Doi:
10.31185/ejuow.Vol8.Iss2.165

\section{Affiliations}

Department, University of

Technology, Baghdad, Iraq

Ministry of Transportation, e General Company for Land Transport, Baghdad

Correspondence

Esraa J Al-mousawi,

3Email: 42360@student.

Revised

Accepted

10.31185/ejuow.Vol8.Iss2.165

\begin{abstract}
Recently, polymer -nanocomposites were used to manufacture durable asphalt mixtures to replace the polymer modified binder, because of the remarkable properties and unique features of nanomaterials compared to conventional materials, such as their wide surface area and small dimensions, making it possible to be utilized as an additive for asphalt paving. Nanosilica particles (NS) are one of the latest minerals which likely integrate useful characteristics, such as huge surface area, good distributions, high absorption levels, high stability, and a high level of purity. Therefore, this paper is interested in studying the characteristics of nanocomposite-polymer modified asphalt. In laboratory work, a pure asphalt $60-70$ penetration grade, has been modified separately with waste polypropylene polymer (WPP), and nanosillica composite polypropylene (NS/WPP) at different concentrations. As a result, two modified binders: waste polypropylene polymer- modified asphalt (WPP-MA), and nanosillica composite polypropylene modified asphalt (NSCPMA) were obtained. Traditional asphalt binder tests were performed for pure and modified binders such as penetration, ductility, flash and fire point test, softening point, and rotational viscosity. Also, storage stability test has been conducted to ensure the storage stability of binders at high temperatures. The results showed an improvement in physical properties and increase in mixing and compaction temperature due to the increase in stiffness of (NSCPMA). The results also indicated that the nanosillica composite polypropylene modified asphalt binders have good storage stability at high
\end{abstract}

Keywords: Brookfield rotational viscometer, composite modified asphalt, mixing and compaction temperature; storage stability.

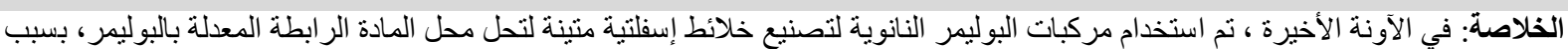

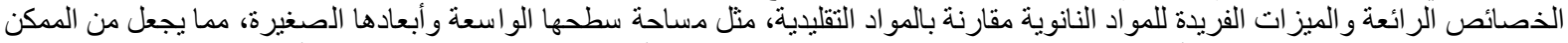

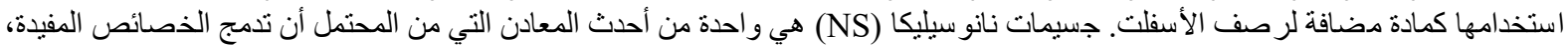

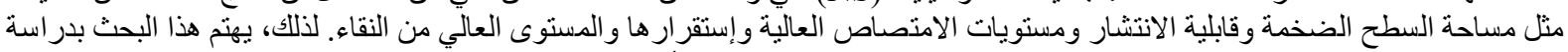

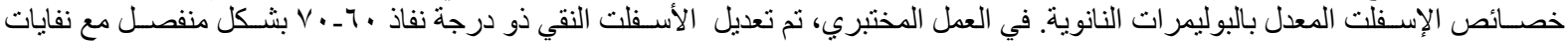

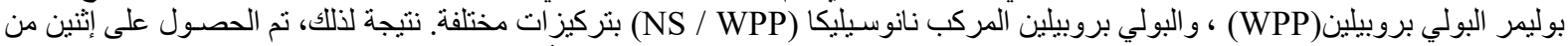

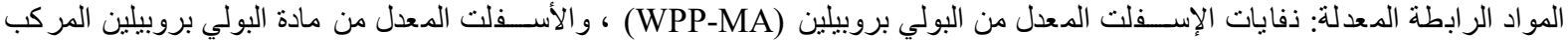

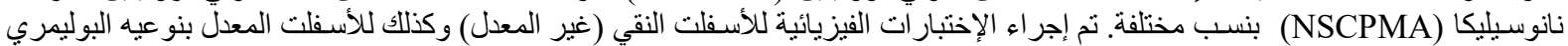

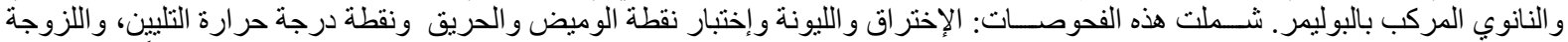

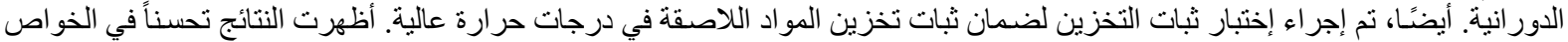

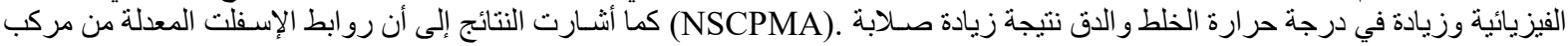

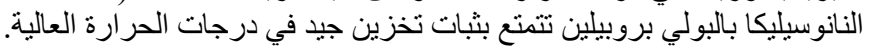

\section{INTRODUCTION}

In combination with the harsh environmental conditions and the growing environmental requirements of the use of the highway network, loads are applied to asphalt pavements during the service life leading to the 
deterioration of the pavement and poor pavement performance, thereby decreasing its service life [1]. So, the need to obtain high-quality bitumen material appeared [2,3]. Modification is a popular method to improve the efficiency of asphaltic pavements [4,5]. There are various modification techniques and additives that are presently utilized in asphalt modifications [6], such as polymers, chemical modifiers, fibers, adhesion improvers, antioxidants, and fillers. Among all attempted or investigated modification methods of bitumen, polymer optimization has been adopted and is the most common [4,7,3]. Polymer modification of the binder was implemented as an option to improve the physical and rheological properties and behaviors of the asphalt binder, leading to improve asphalt mixture performance. The usage of improved asphalt binders has played a significant role in reducing pavement problems and in enhancing asphalt pavements' long-term efficacy [8]. Although the polymer-modified asphalt binder enhances pavement resistance to thermal cracking, fatigue cracking, and rutting resistance, it suffers from a major problem of incompatibility with asphalt and separation in two distinct phases during storage, poor adhesion, and oxidation $[7,4,9,10]$. This subject encourages researchers to investigate new materials and additives to develop the efficiency of polymer-modified bitumen [7].

Nanomaterial additives have acquired considerable attention from pavement researchers for the formulation of durable, high-performance asphalt mixtures due to its superior-excellent properties such as wide surface area, excellent dispersion capacity, high absorption, excellent stability, and high chemical [11-13]. In order to enhance performance properties and long-term attitudes, a new group of asphalt mixtures has been established through a combination of different types of modifiers [14-16], such as polymers including styrene-butadiene-styrene (SBS), and nano-materials including (nano-silica, nano-clay, carbon nanotube).

Nowadays, applications of nano-materials in conjunction with polymers have been positively related to improving the characteristics of bituminous binders due to the excellent properties of tiny nano-material particle sizes, making them more compatible with bitumen $[17,18]$. Several studies found that nanosilica powder has been used to reinforce polymers [15]. Nanomaterial composite/polymer modification reduced both the quantity of nanomaterial and polymer and at the same time, enhanced the compatibility of polymers with bitumen [16], improved the rheological properties, and decreased rut depth [17].

The consistency of asphalt binders influenced by additives, so a reasonable mixing and compaction temperature range should be used to prevent adverse effects due to higher or lower temperatures, as low temperatures mean that the aggregate is not completely covered, and on the other side, asphalt is drained from the mixture if the temperature exceeds the range. In other words, in the construction process, the mixing and compaction temperatures of modified asphalt mixtures are a major consideration[18]. The mixing and compaction temperature ranges that allow the aggregate to bond with the binder and keep the asphalt workability determined by the viscosity of the binders

This paper aims to determine the minimum and maximum range of the mixing and compaction- temperature depending on Brookfield Rotational Viscometer test and evaluates the stability of nanocomposite modified asphalt, besides, performing the conventional asphalt tests.

\section{MATERIALS AND APPARATUS}

\subsection{Asphalt}

In this study, the asphalt binder was gained from AL-Daurah Refinery, with a penetration grade of (60-70). Physical properties of asphalt have been investigated in the laboratory as set out in Table 1.

Table 1. The physical properties of base asphalt and standard limitation

\begin{tabular}{|c|c|c|c|}
\hline Property & Standard & Value & (SCRB/ R9, 2003) specification \\
\hline Penetration $100 \mathrm{gm}, 25^{\circ} \mathrm{C}, 5 \mathrm{sec} .,(0.1 \mathrm{~mm})$ & ASTM D5 & 67 & $60-70$ \\
\hline Ductility $25^{\circ} \mathrm{C}, 5 \mathrm{~cm} / \mathrm{min}$ & ASTM D113 & +140 & $>100$ \\
\hline Softening Point ${ }^{\circ} \mathrm{C}$ & ASTM D36 & 47 & ----- \\
\hline Specific Gravity & ASTM D70 [22] & 1.03 & ----- \\
\hline \begin{tabular}{|l|} 
Flash and \\
Fire point ${ }^{\circ} \mathrm{C}$
\end{tabular} & ASTM D92 & $\begin{array}{l}298^{\circ} \mathrm{C} \\
306^{\circ} \mathrm{C}\end{array}$ & $>232{ }^{\circ} \mathrm{C}$ \\
\hline Rotational Viscosity Pa.sec & ASTM D4402 & $\begin{array}{l}0.430 @ 135^{\circ} \mathrm{C} \\
0.128 @ 165^{\circ} \mathrm{C}\end{array}$ & ----- \\
\hline
\end{tabular}




\subsection{Additives}

In this study, two types of additives have been used to prepare the polymer modified asphalt and nanocomposite modified asphalt, waste polypropylene polymer (WPP), and nanosilica particles (NS).

\subsubsection{Waste Polypropylene Polymer (WPP)}

Polypropylene is a synthetic polymer made from daily waste, it has a chemical formula of C3H6. The chemical and physical properties of waste polypropylene are included in Table 2 by the manufacturer of plastics from which the waste was collected. Figure 1 (a) shows the waste polypropylene polymer (WPP) which was used in this analysis.

Table 2 Physical Properties of Polypropylene According to the plastic factories

\begin{tabular}{|l|c|c|}
\hline \multicolumn{1}{|c|}{ Property } & Unit & Value \\
\hline Density & $\mathrm{g} / \mathrm{cm}^{3}$ & $0.91-0.94$ \\
\hline Softening Point & ${ }^{\circ} \mathrm{C}$ & $140-150$ \\
\hline Melting Point, Tm & ${ }^{\circ} \mathrm{C}$ & 170 \\
\hline
\end{tabular}

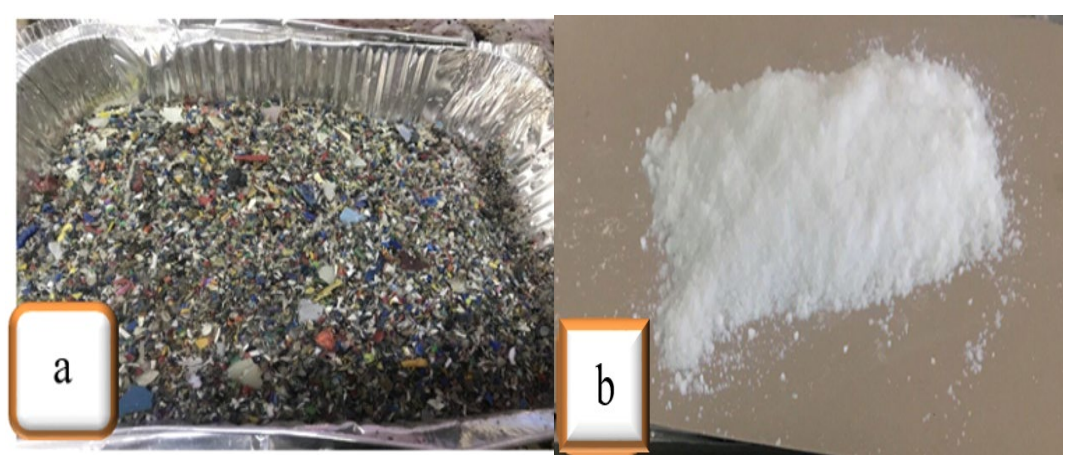

Figure 1 (a) Waste polypropylene polymer, (b) Nanosilica $\mathrm{SiO}_{2}$ powder.

\subsubsection{Nanosilica Particles (NS)}

Nanosilica is a white in color and hydrophobic powder, chemical name silicon dioxide $\left(\mathrm{SiO}_{2}\right)$. Synthetic amorphous silica has been used in a study to modify the binder supplied from AEROSIL Company in North America and shown in Figure 1 (b). The chemical and physical characteristics of nanosilica are listed in Table 3 according to the characteristics of the manufacturer.

Table 3 Physical properties of $\mathrm{Nano}_{\mathrm{SiO}}$ Powder.

\begin{tabular}{|c|c|}
\hline Property & Result \\
\hline Physical form & Powder \\
\hline Colour & White \\
\hline Size, $\mathbf{n m}$ & $11-12$ \\
\hline Bulk Density, g/cm ${ }^{3}$ & $0.1<$ \\
\hline True Density, g/ $\mathrm{cm}^{3}$ & 2.4 \\
\hline Specific surface area, $\mathrm{m}^{2} / \mathrm{g}$ & 200 \\
\hline Purity, \% & 99.8 \\
\hline PH & $3.7-4.5$ \\
\hline
\end{tabular}




\subsubsection{Mixer Type}

To obtain a homogeneous mixture, two laboratory mixers were used in the mixing technique to prepare the nanosilica composite polymer modified asphalt which are: the classic mechanical mixer, and the homogeneous shear mixer. Figure 2 shows the mixers used in this study.

\section{- Mechanical Mixer}

Apparatus with a steady motor rotational speed measured at $1370 \mathrm{rpm}$ during the process of mixing. Mixing timebased on the opinion of the operator and the additive kind. This mixer was used as the first step in the process of preparation of a composite modified asphalt.

\section{- Homogenizer Shear Mixer}

The homogenizer shear mixer shown in Figure 2 was purchased specifically for this study with rotational energy (mixing speed) 27,000 rpm from IKA-WERK Company to ensure a homogeneous mix. In this analysis, high engine speed reduced the time taken to mix the asphalt with additives and obtain a homogeneous blend of nanosilica composite modified asphalt.

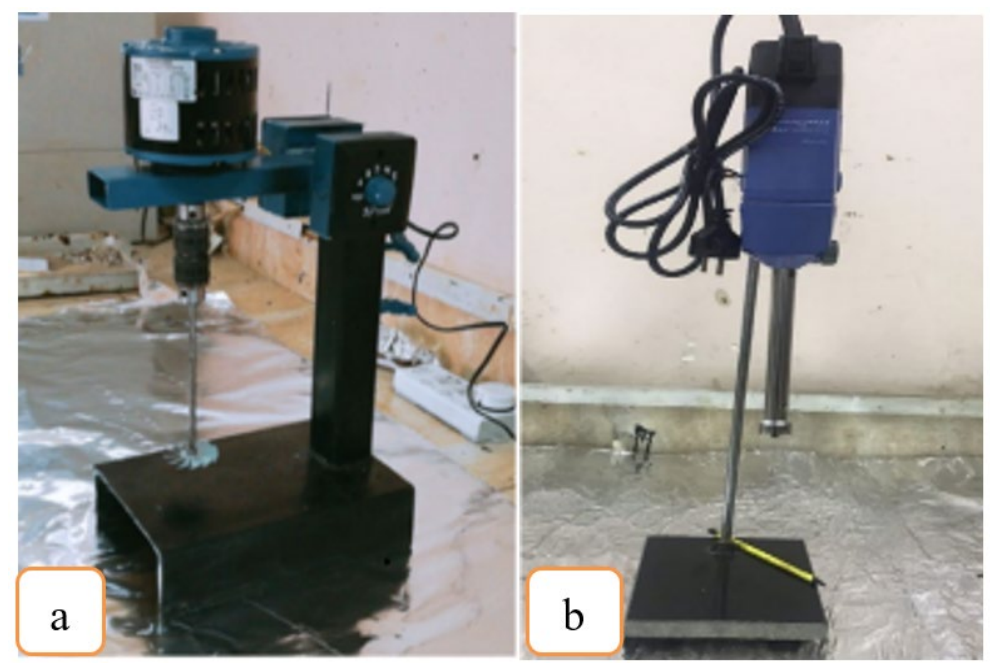

Figure 2 Mixers types, (a) Mechanical mixer, and (b) Homogenizer mixer

\section{LABORATORY WORK}

\subsection{Sample Preparation}

Initially, asphalt 60-70 and WPP polymer are mixed for 1 hour at mixing temperature $(165 \pm 5){ }^{\circ} \mathrm{C}$ using a mechanical mixer to produce WPP-modified asphalt. Depending on volumetric properties, marshal stability, Marshall flow values of asphalt mixtures, and physical test of asphalt binders modified by four different percentages of waste polypropylene polymer $(1,2,3$, and 5$) \%$ by binder weight, the concentration of $2 \%$ of WPP has been selected as optimum content of the polymer.

Next, to produce a nanocomposite polypropylene modified asphalt (NSCPMA) binders, 2\% of WPP with different percentages of nanosilica $(0.5,1$, and 2$) \%$ by weight of asphalt were added to a preheated binder to $145{ }^{\circ} \mathrm{C}$. NS / WPP was applied together to a preheated binder and blended in the mechanical mixer with $1370 \mathrm{rpm}$ for $30 \mathrm{~min}$ at $(165 \pm 5){ }^{\circ} \mathrm{C}$ and, then it transferred to high shear mixing device has a rotational speed of $27000 \mathrm{rpm}$ at $(165 \pm 5)$ ${ }^{\circ} \mathrm{C}$ for 10 min to ensure homogeneity of the mix.

Polymer modified asphalt (WPP-MA) and nanosilica composite polymer modified asphalt samples (NSCPMA) were subjected to asphalt traditional physical tests including penetration, softening point, ductility, and flash and fire points as recommended by ASTM. Also, rotational viscosity and storage stability tests were performed. 


\subsection{Tests}

\subsubsection{Penetration Test}

As stated by ASTM D5 [19], a penetration test for pure and modified asphalt binder samples was conducted. The penetration test is used to determine the consistency and hardness of the asphalt, with higher values of penetration suggesting a softer degree of consistency. The depth of penetration is measured in units of $(0.1) \mathrm{mm}$.

\subsubsection{Softening Point Test}

The purpose of this test is to identify the temperature at which the asphaltic material consistency has begun to change and the tendency to flow. As maintained by ASTM D36 [21], for pure and modified binder samples, softening point testing was performed.

\subsubsection{Ductility Test}

In order to measure the tensile feature of asphaltic materials and to show the cohesion of the asphalt cement binder, a ductility test is also performed on the asphalt samples. Asphalt binder with a high ductility value is generally considered to have good low-temperature service efficiency and better recovery ability during stress application [17]. The test was done according to the standard ASTM D113 [20].

\subsubsection{Flash and Fire Points}

The flash point is the minimum temperature that allows asphalt surface vapor to flash suddenly under an open flame exposure. The test was performed as stated in ASTM D92 [25] via using the Cleveland open cup apparatus.

\subsubsection{Rotational Viscosity Test (RV)}

In general, the asphalt binder's fluidity is assessed by viscosity. The purpose of the rotational viscosity test is to define the temperature that allows the asphalt mixture to reach and sustain asphalt workability and to ensure bonding during the mixing and compaction process between the asphalt mixture components. According to ASTM D4402 [24], the testing was conducted using the Brookfield Rotational Viscometer to evaluate the viscosity at $135^{\circ} \mathrm{C}$ and $165^{\circ} \mathrm{C}$ of each binder form.

\subsubsection{Storage Stability Test}

In order to avoid phase separation at high temperatures, storage stability tests are performed to help to assess the stability of a binder. in this report, the storage stability test of modified asphalt was adopted as per ASTM D7173 [26].

Firstly, the modified asphalt samples were heated in the oven until sufficiently fluid to pour. $50 \pm 0.5 \mathrm{~g}$ has been poured into a heat resistant glass tube $25 \mathrm{~mm}$ diameter by $125-140 \mathrm{~mm}$ length, then put vertically in an oven maintained a temperature of $163 \pm 5^{\circ} \mathrm{C}$ for $48 \pm 1$ hour. Then, the tube was put immediately in a freezer maintained a temperature of $-10 \pm 10{ }^{\circ} \mathrm{C}$ for a duration of 4 hours minimum with keeping the tube in a vertical position.

Finally, after spending time, the tube was removed from the freezer and placed on a hard flat surface, and cut into 3 parts of roughly equal length; the difference in temperature of the softening point between the top and bottom segments is noticed. When the difference between the softening points of the top and bottom parts is less than 2.5 ${ }^{\circ} \mathrm{C}$, the blend is considered to be stable.

\section{RESULTS AND DISCUSSION}

\subsection{Physical Tests}

The laboratory experimental findings have been shown in Table 4. It can easily be observed that by incorporating waste polypropylene and different percentages of nanosilica, the penetration values decrease, although the temperature of the softening point, flash \& fire point, and rotational viscosity increase with a rise in the content of nanosilica compared to pure and WPP-modified binders. Also, these findings indicate an increase in the rigidity of modified composite asphalt. These results are due to the saturation of nanosilica particles with light-volatile asphalt components, and that the nanosilica particles are stiffer than the asphalt, which increases the stiffness of modified asphalt [27]. The hardness of the NSCPMA binders is also greater than that of the pure and WPP-MA, 
leading to an enhancement in the rigidity of the improved asphalt binder. Also, it can be seen that the addition of WPP combined with NS increased the ductility values as the concentration of nanosilica increased. This increase can be explained by that the addition of NS/WPP contributes to an improvement in asphaltic flexibility that represents the ability to recover after loading [17].

Table 4 Conventional tests for the pure asphalt, (WPP, and NS/WPP) modified binders.

\begin{tabular}{|c|c|c|c|c|c|c|}
\hline Properties & Condition & $\begin{array}{c}\text { Pure } \\
\text { Asphalt }\end{array}$ & $\begin{array}{c}2 \% \\
\text { WPP }\end{array}$ & $\begin{array}{c}0.5 \% \mathrm{NS} \\
+2 \% \mathrm{WPP}\end{array}$ & $\begin{array}{c}1 \% \mathrm{NS} \\
+2 \% \mathrm{WPP}\end{array}$ & $\begin{array}{c}2 \% \mathrm{NS} \\
+2 \% \mathrm{WPP}\end{array}$ \\
\hline $\begin{array}{l}\text { Penetration } \\
(0.1 \mathrm{~mm})\end{array}$ & (a) $25^{\circ} \mathrm{C}$ & 67 & 49.1 & 38 & 35 & 28.3 \\
\hline $\begin{array}{l}\text { Softening point } \\
\left({ }^{\circ} \mathrm{C}\right)\end{array}$ & $5^{\circ} \mathrm{C} / \mathrm{min}$ & 47 & 54 & 54.5 & 58.75 & 61 \\
\hline $\begin{array}{l}\text { Ductility } \\
(\mathrm{cm})\end{array}$ & (a) $25^{\circ} \mathrm{C}$ & 140 & 133 & 135 & 137 & 138.5 \\
\hline $\begin{array}{l}\text { Flash point } \\
\text { \&Fire point }\end{array}$ & $\begin{array}{l}{ }^{\circ} \mathrm{C} \\
{ }^{\circ} \mathrm{C}\end{array}$ & $\begin{array}{l}298 \\
308\end{array}$ & $\begin{array}{l}308 \\
315\end{array}$ & $\begin{array}{l}328 \\
344\end{array}$ & $\begin{array}{l}332 \\
345\end{array}$ & $\begin{array}{l}340 \\
347\end{array}$ \\
\hline Rotational Viscosity (Pa.sec) & $\begin{array}{l}\text { (a) } 135^{\circ} \mathrm{C} \\
\text { (a) } 165^{\circ} \mathrm{C}\end{array}$ & $\begin{array}{l}0.430 \\
0.128\end{array}$ & $\begin{array}{l}0.662 \\
0.155\end{array}$ & $\begin{array}{l}0.965 \\
0.212\end{array}$ & $\begin{array}{l}1.025 \\
0.222\end{array}$ & $\begin{array}{l}1.320 \\
0.271\end{array}$ \\
\hline
\end{tabular}

\subsection{Storage Stability Test}

Figure 4 illustrates the effect of additives on the stability of modified asphalt during storage at high temperatures. It can be seen from Table 5 that the variance in softening point temperature between the top and bottom sections of all samples of asphalt modified is within the standard limit specifying by $\left(<2.5^{\circ} \mathrm{C}\right)$. This result agrees with [28]. That means all samples didn't suffer poor storage stability. Polymers are known to suffer from the storage stability problem. In this research, this issue has still not appeared, which is attributed may be due to the low content of the polymer, for this reason, all additive percentages consider ideal choice as modifiers. The results of this study are compatible with [29], who used PP fibers in bitumen with proportions of $(0.3,0.6,1,2,4,6) \%$.

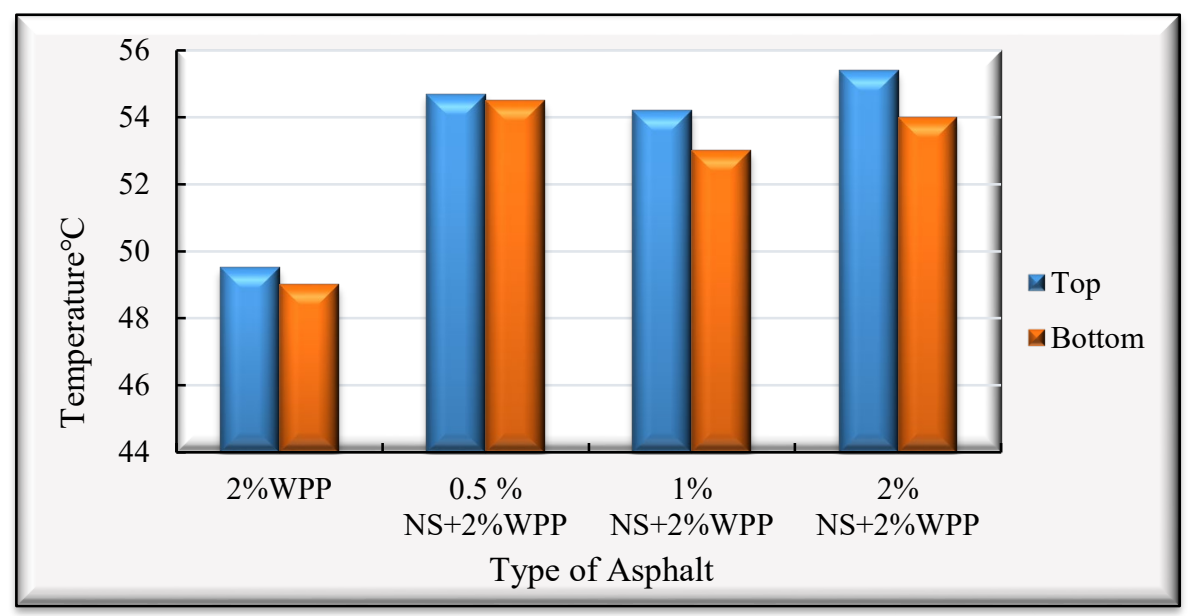

Figure 4 Storage Stability Test Results

Table 5 Storage stability test results

\begin{tabular}{|l|c|c|c|}
\hline \multirow{2}{*}{ Type of asphalt } & \multicolumn{2}{|c|}{$\begin{array}{c}\text { Softening Point } \\
\text { Temperature, }\end{array}$} & \multirow{2}{*}{ V } \\
\cline { 2 - 3 } & Top & Bottom & \\
\hline $\mathbf{2 \% W P P}$ & 49.5 & 49 & 0.5 \\
\hline $\mathbf{0 . 5} \% \mathbf{N S}+\mathbf{2 \% W P P}$ & 54.7 & 54.5 & 0.2 \\
\hline $\mathbf{1 \%}$ NS+2\%WPP & 54.2 & 53 & 1.2 \\
\hline $\mathbf{2 \%} \mathbf{N S}+\mathbf{2} \%$ WPP & 55.4 & 54 & 1.4 \\
\hline
\end{tabular}




\subsection{Mixing and Compaction Temperature}

A significant consideration in the construction process is the mixing and compaction -temperatures of modified asphalt mixtures. The temperature should be selected within the specified range, as the lower temperatures cause weaken coated aggregate particles. On the other hand, the asphalt drains out of the mixture, if an increase in the temperature over the limits [18]. The relation between viscosity and temperature should be drawn in order to assess the blending and compaction temperature for asphalt mixtures. Figures 5, 6, 7, 8, and 9 represent the temperature -viscosity relationship for pure and modified asphalt binder. According to Superpave System, the mixing and compaction temperature range have been determined at rotational viscosity $(0.17 \pm 0.02) \mathrm{Pa}$.sec and $(0.28 \pm 0.03) \mathrm{Pa} . \mathrm{sec}$ at $135^{\circ} \mathrm{C}$ and $165^{\circ} \mathrm{C}$, respectively and listed in Table 6 . It can be shown that the mixing and compaction temperatures increased with an increased in nanosilica concentration. These effects are mainly attributable to the diffusion and permeation of nanosilica powder in the asphalt binder, which helps to absorb light volatility material in the maltene portion and increase the asphaltene part of the asphalt binder [27].

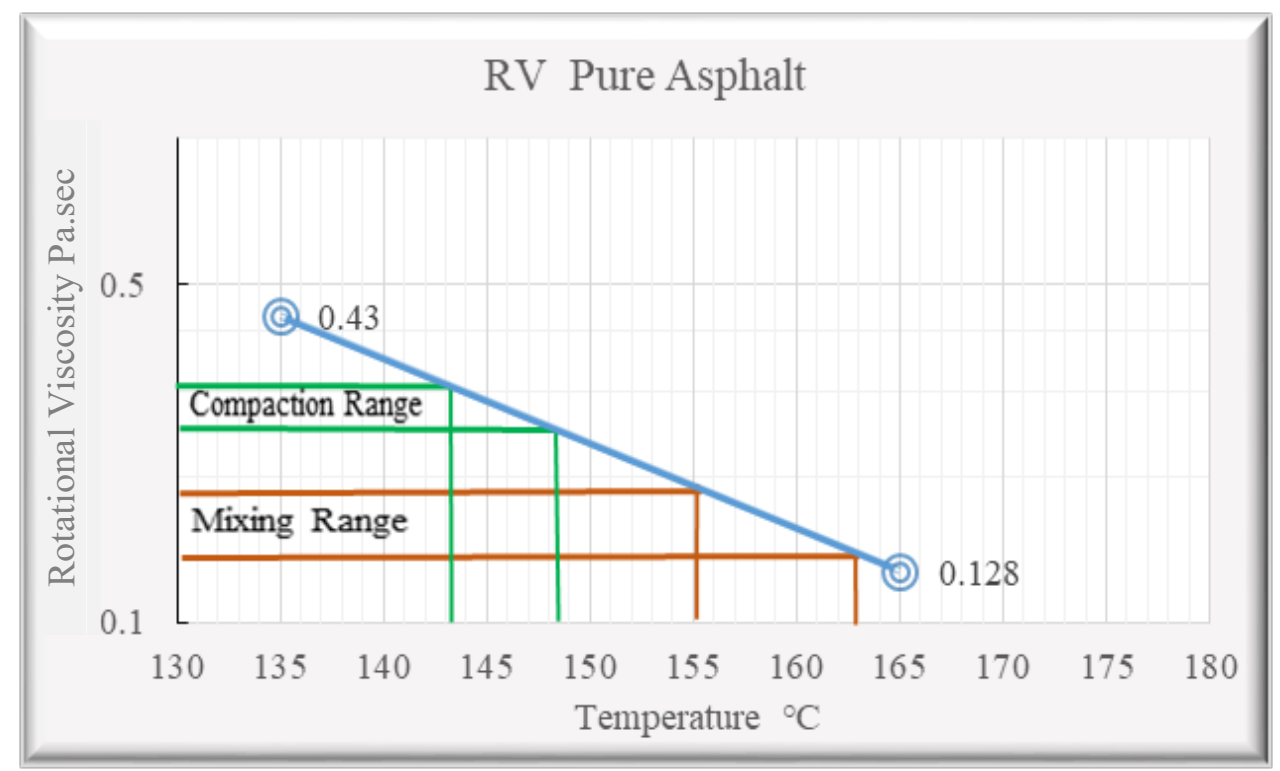

Figure 5 Temperature-viscosity chart of pure asphalt (60-70)

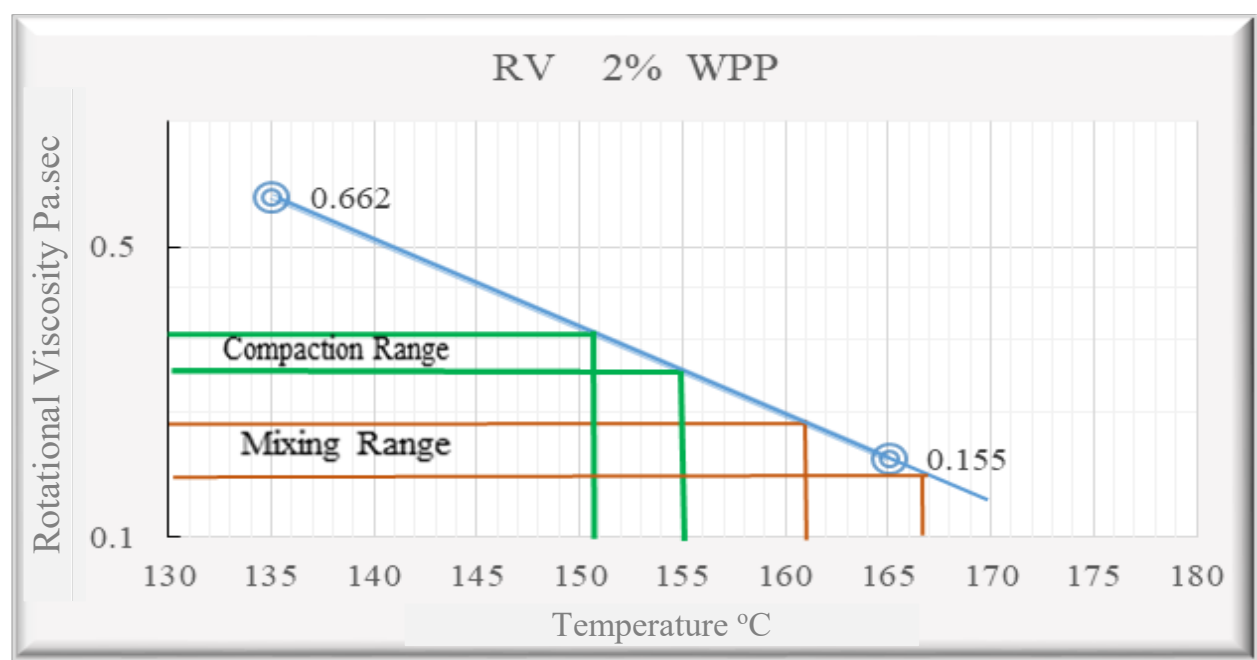

Figure 6 Temperature-viscosity chart for 2\% WPP modified asphalt 


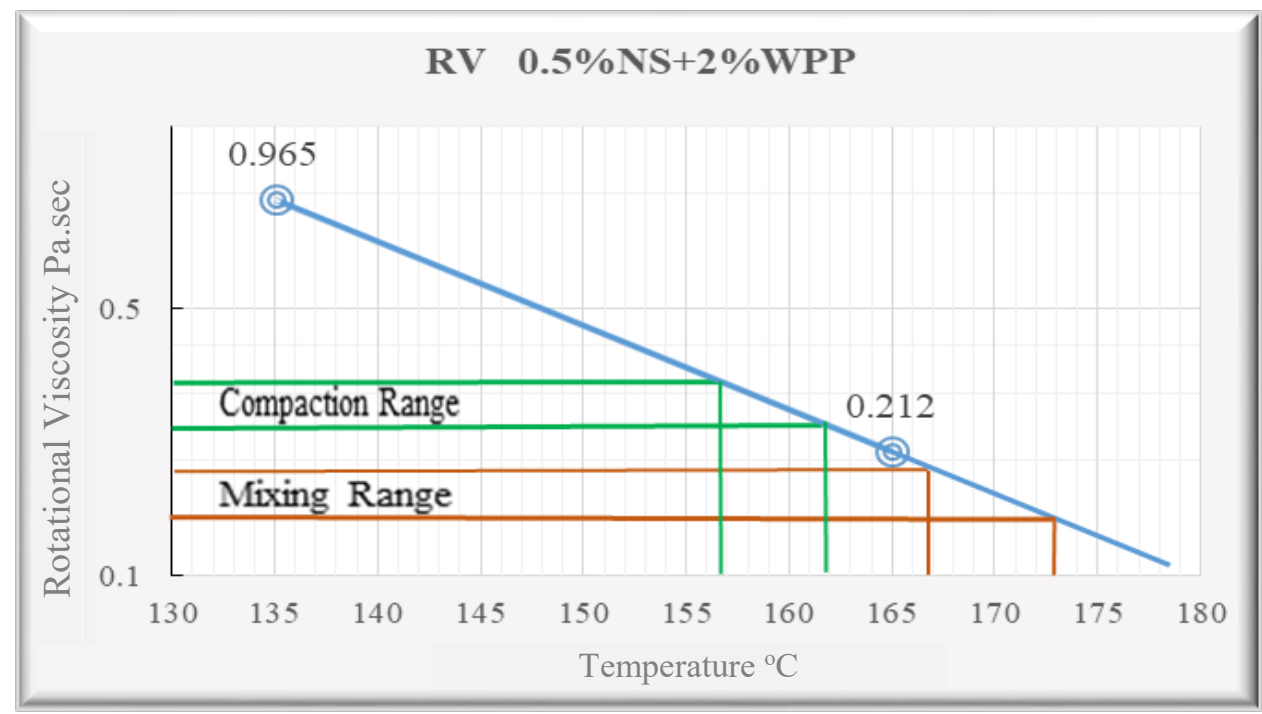

Figure 7 Temperature-viscosity chart for $0.5 \% \mathrm{NS}+2 \% \mathrm{WPP}$ composite modified asphalt

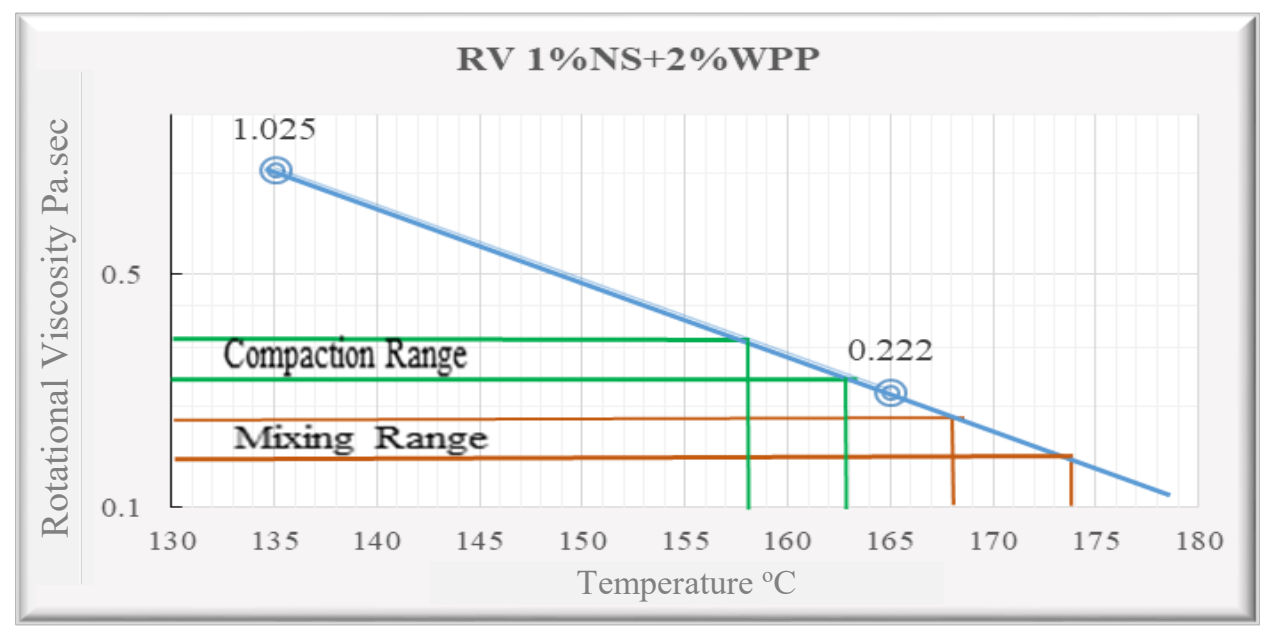

Figure 8 Temperature-viscosity chart for $1 \% \mathrm{NS}+2 \% \mathrm{WPP}$ composite modified asphalt

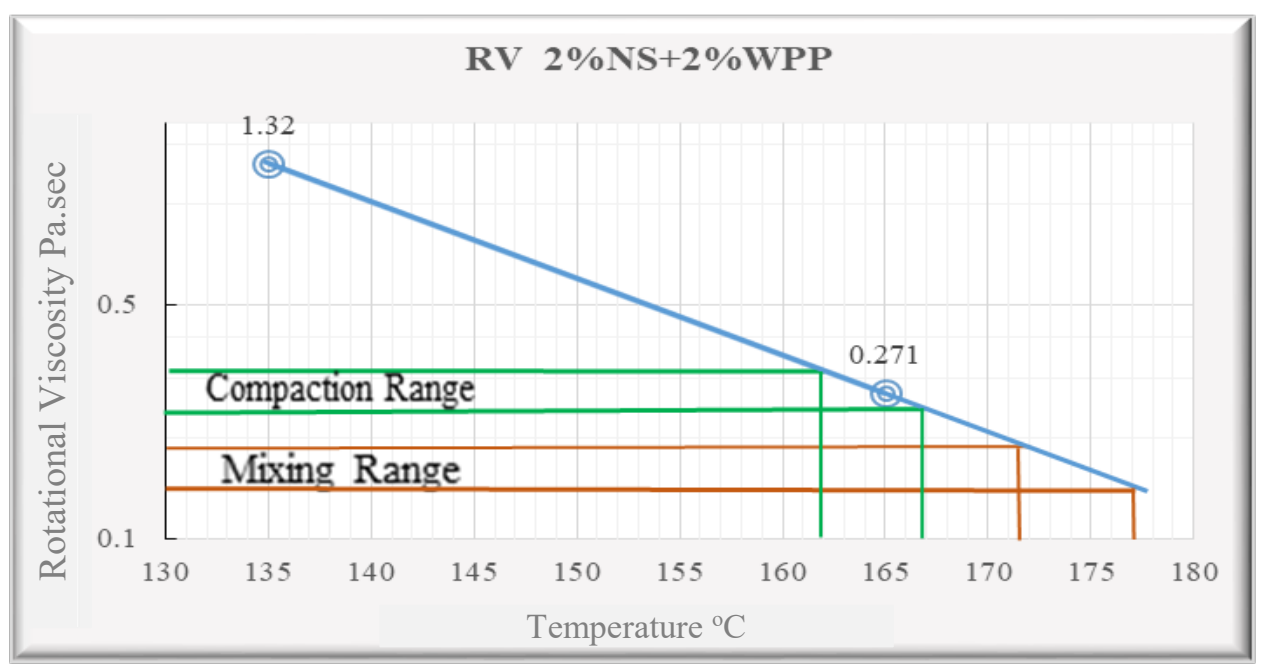

Figure 9 Temperature-viscosity chart for $2 \% \mathrm{NS}+2 \% \mathrm{WPP}$ composite modified asphalt 
Table 6 mixing and compaction temperature of pure and modified asphalt binders

\begin{tabular}{|c|c|c|c|c|}
\hline \multirow{2}{*}{ Type of Asphalt } & \multicolumn{2}{|c|}{$\begin{array}{c}\text { Mixing } \\
\text { Temperature, }{ }^{\circ} \mathrm{C}\end{array}$} & \multicolumn{2}{|c|}{$\begin{array}{c}\text { Compaction } \\
\text { Temperature, }{ }^{\circ} \mathrm{C}\end{array}$} \\
\hline & Min. & Max. & Min. & Max. \\
\hline Pure Asphalt & 155 & 163 & 143 & 148.5 \\
\hline $2 \% W P P$ & 161 & 167 & 151 & 155 \\
\hline $0.5 \% \mathrm{NS}+2 \% \mathrm{WPP}$ & 167 & 173 & 157 & 162 \\
\hline $1 \% \mathrm{NS}+2 \% \mathrm{WPP}$ & 168 & 174 & 158 & 163 \\
\hline $2 \% \mathrm{NS}+2 \% \mathrm{WPP}$ & 171.5 & 177 & 162 & 167 \\
\hline
\end{tabular}

\section{CONCLUSIONS}

The following conclusions are taken from the findings of the analysis

1. The penetrating value of the asphalt binder decreases when WPP-polymer has been added, and this decrease continues with the addition of NS particles, suggesting increased hardness and stiffness of the NSCPMA binders.

2. The softening point of the NSCPMA binders is more than the softening point of the WPP-MA, indicating the hardness of NSCPMA binders are more than the WPP- modified asphalt due to the adding of NS particles.

3. Asphalt ductility decreasing with the addition of WPP polymer whereas it increased with an increasing percentage of nanosilica for NSCPMA binders, this implies an improvement in asphalt elasticity with an increase in NS content and an increase in tension resistance.

4. Rotational viscosity and flash point increased with an increasing percentage of nanosilica for NSCPMA binders due to increased hardness and stiffness at moderate temperatures of the NSCPMA binders.

5. NSCPMA binders showed good storage stability at high temperatures.

6. The mixing and compaction temperature of the NSCPMA increased as NS content increased.

7. Nanosilica can reinforce the polymer-modified asphalt binder and increase recovery capability during stress application

\section{REFERENCES}

1 Airey, G. D. (2003). Rheological properties of styrene butadiene styrene polymer modified road bitumens 2 . Fuel, 82(14), 1709-1719..

2 Isacsson, U., \& Lu, X. (2004). Testing and appraisal of polymer modified road bitumens. Bitum. Bind. Mixes, 17(9).

3 J. Read, D. Whiteoak, and R. N. Hunter, (2003). The shell bitumen handbook. Thomas Telford.

4 Zhu, J., Birgisson, B., \& Kringos, N. (2014). Polymer modification of bitumen: Advances and challenges. European Polymer Journal, 54, 18-38.

5 Bala, N., \& Kamaruddin, I. (2016). Physical and storage stability properties of linear low density polyethylene at optimum content," in Engineering Challenges for Sustainable Future, 395(399): 395-399. ROUTLEDGE in association with GSE Research.

6 Mashaan, N. S., Ali, A. H., Karim, M. R., \& Abdelaziz, M. (2014). A review on using crumb rubber in reinforcement of asphalt pavement. The Scientific World Journal, 2014.

7 Yusoff, N. I. M., Breem, A. A. S., Alattug, H. N., Hamim, A., \& Ahmad, J. (2014). The effects of moisture susceptibility and ageing conditions on nano-silica/polymer-modified asphalt mixtures. Construction and Building Materials, 72, 139-147. 
8 Yang, J., \& Tighe, S. (2013). A review of advances of nanotechnology in asphalt mixtures. Procedia-Social and Behavioral Sciences, 96, 1269-1276.

9 Q. Xu, H. Chen, and J. A. Prozzi, (2010).Performance of fiber reinforced asphalt concrete under environmental temperature and water effects. Constr. Build. Mater., 24 (10): 2003-2010.

10 B. Amini, M. J. Rajabbolookat, A. Abdi, and R. Salehfard, (2017). Investigating the influence of using nanocomposites on storage stability of modified bitumen and moisture damage of HMA," Pet. Sci. Technol., 35(8): 800-805.

11 L. P. Singh, S. R. Karade, S. K. Bhattacharyya, M. M. Yousuf, and S. Ahalawat, (2013).Beneficial role of nanosilica in cement based materials-A review," Constr. Build. Mater., 47 :1069-1077.

12 S. Sadeghpour, B. Dabir, A. Ehsan, and A. Moeini, (2010).Rheological properties and storage stability of bitumen / SBS / montmorillonite composites," Constr. Build. Mater., 24 (3):300-307, doi: 10.1016/j.conbuildmat.2009.08.032.

13 Z. You et al., (2011). Nanoclay-modified asphalt materials: Preparation and characterization," Constr. Build. Mater., 25(2):1072-1078.

14 N. Bala, I. Kamaruddin, M. Napiah, and N. Danlami,(2017).Rheological and rutting evaluation of composite nanosilica/polyethylene modified bitumen. in IOP Conference Series: Materials Science and Engineering, 201(1):12012.

15 Chrissafis, K., Paraskevopoulos, K. M., Papageorgiou, G. Z., \& Bikiaris, D. N. (2008). Thermal and dynamic mechanical behavior of bionanocomposites: fumed silica nanoparticles dispersed in poly (vinyl pyrrolidone), chitosan, and poly (vinyl alcohol). Journal of applied polymer science, 110(3), 1739-1749.

$16 \mathrm{Yu}$, R., Fang, C., Liu, P., Liu, X., \& Li, Y. (2015). Storage stability and rheological properties of asphalt modified with waste packaging polyethylene and organic montmorillonite. Applied Clay Science, 104, 1-7.

17 Alhamali, D. I., Wu, J., Liu, Q., Hassan, N. A., Yusoff, N. I. M., \& Ali, S. I. A. (2016). Physical and rheological characteristics of polymer modified bitumen with nanosilica particles. Arabian Journal for Science and Engineering, 41(4), 1521-1530.

18 Joni, H., \& Shaker, E. (2017). Determination of the acceptable range of mixing and compaction temperatures for modified asphalt mixture with styrene butadiene styrene (SBS). International Journal of Current Engineering and Technology, 7(5).

19 D. ASTM, (2013).Standard test method for penetration of bituminous materials. USA, ASTM Int.

20 A. D113, (2007).Standard test method for ductility of bituminous materials. Annu. B. Stand.

21 D. ASTM, (2014). Standard test method for softening point of bitumen (ring-and-ball apparatus). Am. Soc. Test. Mater. West Conshohocken, PA, USA.

22 A. International ASTM D70-09, (2009). Standard Test Method for Density of Semi-Solid Bituminous Materials (Pycnometer Method).. ASTM International West Conshohocken, PA.

23 D. ASTM,70 (2003) Standard Test Method for Specific Gravity and Density of Semi-Solid Bituminous Materials (Pycnometer Method)," Annu. B. ASTM Stand., 4.

24 D. ASTM,(2015).Standard test method for viscosity determination of asphalt at elevated temperatures using a rotational viscometer. in American Society for Testing and Materials.

25 A. D92, (2016).Standard test method for flash and fire points by Cleveland open cup tester," Annu. B. Stand..

26 D. ASTM, "7173 (2005) Standard Practice for Determining the Separation Tendency of Polymer from Polymer Modified Asphalt," Annu. B. ASTM Stand., 4

27 Taherkhani, H., \& Afroozi, S. (2016). The properties of nanosilica-modified asphalt cement. Petroleum Science and Technology, 34(15), 1381-1386.

28 Bhat, F. S., \& Mir, M. S. (2019). Performance evaluation of nanosilica-modified asphalt binder. Innovative Infrastructure Solutions, 4(1), 63.,.

29 Zachariah, J. P., Sarkar, P. P., Debnath, B., \& Pal, M. (2018). Effect of polypropylene fibres on bituminous concrete with brick as aggregate. Construction and Building Materials, 168, 867-876. 